\title{
Bayesian acyclic network based environmental footprint risk assessment system for oil and gas industry
}

\author{
Agnel Cyriac Philip, Egils Ginters, Dilara Basdogan \\ Riga Technical University, \\ Riga, LV-1658 \\ Latvia
}

Received: January 22, 2021. Revised: July 20, 2021. Accepted: August 7, 2021. Published: August 11, 2021.

\begin{abstract}
The oil and gas industry is the eighth largest in the world. Its market size is expected to grow from USD 4.6 trillion in 2020 to USD 5.9 trillion in 2021, and in 2025 it will reach USD 7.4 trillion. The oil and gas industry is the backbone of today's economy, and it is difficult to imagine that the share of the industry's influence in world economy could decrease soon. Oil and gas production and supply chains pose significant environmental risks. Various methods are used to assess the risks of the industry's impact on the environment. In most cases, they are labor-intensive and non-interactive, which reduces the effectiveness of scenario testing. The article dealt with a new approach for analyzing different hazard risk scenarios based on Bayesian acyclic networks, looking at the supply chain as a socio-technical system, the sustainability of which is determined by the systemic impact on three pillars - business, society and environment. This article focuses on the environmental component. The article aims at introduction the audience, i.e., investors, business leaders and territorial development policy planners, the use of the method for assessing the systemic environmental risks of supply chains in the oil and gas industry.
\end{abstract}

Keywords-Bayesian networks, socio-technical systems, systems applications, oil and gas industry, environmental risks assessment, scenarios modeling.

\section{INTRODUCTION}

A CCORDING to British Petroleum [1] review, by the end of 2019, the estimated oil reserve in the world was over 244.6 billion tones with Middle East contributing nearly 50\% of the total share. Venezuela had the largest oil reserve in the world with $17.5 \%$ and Saudi Arabia was second with 17.2\%.
Among the total share, OPEC and OECD controlled 171.8\% and $38.3 \%$ respectively, but European Union controlled just $0.7 \%$ of total oil reserve of the world. Oil production has increased up to $25 \%$ in the last 20 years, but the global oil reserve has also become $60 \%$ larger [2].

By British Petroleum assessment [1] of 2018, USA has produced over 15 million barrels per day. Saudi Arabia and Russia closely followed with over 12 million and 11 million barrels per day respectively.

The USA also is the largest consumer of oil with 19.4 million barrels per day followed by China with over 14 million barrels per day [3]. According to EIA [4] 2019 data, $68 \%$ of total consumption in the USA was used for transportation, $26 \%$ for industrial purposes, $3 \%$ for residential purposes, $2 \%$ for commercial purposes and less than $1 \%$ for electricity generation.

Oil and gas industry are one of the largest industries in the world [5], [6], but their attempt towards achieving the sustainability towards the environment requires improvement. For several decades' oil and gas industry had significant impact on the environment due to exploration and exploitation [7]. Environmental risks could emerge along all supply chain from extraction and refinery till distribution and delivery to customer, and affect florae and faunae, health of human beings, ground and atmosphere, and climate.

The result and impact of the supply chain as a joint operation of a socio-technical system is determined by the interaction of its logical and physical structure. The logical structure includes rules, guidelines, laws, methodologies, etc. that distinguishes a particular supply chain from any other similar supply chain in the oil and gas industry. A physical structure is an environment that provides the implementation of a logical structure, such as oil extraction / refining equipment, transportation, computer equipment, etc. The impact on the environment is the overall result of the system functioning, so the authors will use a holistic approach rather 
than reductionism, that is, a separate analysis of each component of the overall system will not be performed. In complex systems with a large number of stochastic factors and their significant impact, the correct functioning of individual system elements does not guarantee the correct operation of the overall system. The above considerations are typical for socio-technical systems, where the impact of the human factor is difficult to assess and can upset the stability of the system.

Various environmental risks assessment methods are used in the oil and gas industry, such as Risk Screening Process [8], Risk Evaluation Matrix design [9], Hazard Environment and Safety (HES) Risk Management Process [10], Hazard and Operability Study (HAZOP) [11] and others. The main disadvantages of the methods are their static nature and labor intensity of processing the results, as well as they are not interactive. In some cases, the assistance of professionals is needed to translate the forecasted result. The methods are not easy to use for operational risk management if you must answer the question, what will happen if?

The aim of the article is to introduce the audience with potential hazards in the oil and gas industry supply chains and with an interactive and efficient environmental impact risk assessment method based on Bayesian acyclic networks.

The risk assessment method provides fast and interactive risk assessment of various development scenarios, improving decision-making both during policy planning and prevention of real threats and their consequences.

The results of the study will be useful for both regional policy planners and risk managers in oil and gas companies.

\section{SUPPLY CHAIN IN OIL AND GAS INDUSTRY}

A typical supply chain covers the way form raw material production (preparation, extraction, refining) to transportation, storage (warehouses) and distribution. The efficiency of the supply chain is determined by the successful cooperation of the technical and social component while maintaining a neutral impact on the environment, because of which the chain can be considered a classic example of a socio-technical system [12].

Supply chain in oil and gas industry mainly comprises of three segments - upstream, midstream and downstream [13]. Site exploration, testing, drilling, extractions etc. operations are part of upstream segment. Transportation, refinery and storage of oil and gas products are the main features in the midstream segment. Downstream segment consists of turning the finished product into services and finally getting into the hands of consumers.

The main stages are following:

1) Oil and gas production. The most complicated, timeconsuming, and dangerous process as the pressure trapped under the earth's surface could be immense. It should be monitored and controlled throughout the drilling and extraction process to avoid any kind of potential hazardous.

2) Transportation (towards refinery). There are mainly three modes of transport:

a. Pipelines. This is a very convenient way of transporting as pipelines are fast, cheap, and reliable [14]. The pipelines are pressure and temperature controlled and tested to avoid any type of leakage or spills which could affect the environment. For example, Keystone XL, a North American energy company, has transported over 700,000 barrels of oil in just a single day [14].

b. Ships. The marine transportation in 2019 was responsible for $80 \%-90 \%$ of the world's total trade [15], and about $29 \%$ of the carriers in 2018 were oil tankers. Despite being slow maritime transport is cheap, can carry large amount of oil and is the most reliable way to carry oil to any part of the globe.

c. Rails. Railways can be used to transport large volumes of oil. Railway tanks are less prone to any leaks or spills compared to other modes of transport. Rail transport combined with other means of transportation could be very cost effective and beneficial rather than operating on itself.

3) Refining. This is the margin stage where the crude oil is processed into different petroleum products like fossil fuels, petroleum jelly, oils, lubricants etc. Each petroleum product is manufactured at different temperatures using certain chemical catalysts. The set of processes (cracking, reforming, distillation, alkylation, pyrolysis) are carried out in the refineries.

4) Transportation (from refinery). Besides the pipeline, marine and rail transportation the trucks are used to transport small number of oils via road freight at shorter distance.

5) Storage. There are products are managed throughout the supply chain. Some of the oil is also stored in terms of reserve. In March 2020 [16] around 3.4 billion barrels of oil storage being used worldwide. Saldanha Bay in South Africa is one of the world largest strategic storage facilities for crude oil with an estimated holding capacity of 60 million barrels [17].

6) Distribution. The fuels are transported from the storage to their respective terminals, gas stations and point of sales. Different intermodal transportation is used, and most companies rely on third party logistics. Middle East in 2019 has the highest share in the distribution of oil globally with $31.9 \%$ [18].

The activities on supply chain of oil and gas industry either directly or indirectly interact with the environment. Even though petroleum industry is an important part of the economy, their impact is often negative. Pollution [19] contaminates air, water, and ground through the emission of wastewater, gas emissions etc.

Could be mentioned some of the well-known accidents and disasters happened within oil and gas industry from around the world.

In 1979 due to the lack of mud circulation in Ixtoc-1 drilling well [20], [21] located in the southern Gulf of Mexico, the oil and gas started slowing to the surface uncontrollably and lead to fire and explosion. It was estimated that over 3 million barrels of oil was released during this accident. The oil spill 
seriously affected the marine ecosystem due to its chemical toxicity.

The drilling rig Alexander L. Kielland [20], [22] located in Scotland was struck by disaster in March 1980. The failure was due to welding defects in the underwater pillars of the rig.

Piper Alpha [23] was an oil rig located in the north-east of Scotland. In July 1988, due to a faulty blind flange assembly which resulted in a leak of gas, the rig exploded. Technical faults and poor judgment from the management were the major reasons for the disaster [24].

The Persian Gulf oil spill in January 1991 [25] happened due to war. Around 240 million gallons of crude oil was spilled in the Persian Gulf which resulted in the largest oil spills in the history.

Deepwater Horizon [26] was an offshore drilling rig located in an area of the Gulf of Mexico. The explosion happened on April 20, 2010, was the largest oil spill in the USA history. The amount of oil spilled was enough to cause a widespread contamination effects for the marine life ecosystems and the shoreline. It was estimated that over 4,9 million barrels of oil was leaked into the ocean. The long-term environmental impact of the oil spill was even worse as it effected multitude of other sectors like tourism and fishing sector.

Risks on supply chain in gas and oil industry, for example, geological structure risks [27], seismic activities [28] and security risks [25], [29] cannot be eliminated, but they can be managed [7]. If hazards/threats happen then the set of accidents can be observed, for example, equipment failures [30], emissions [31], leaks and spills [23], [31], fire and explosions [20], [32]. Further the set of accidents cause appropriate environmental impacts/effects which could be mentioned as follows:

1) Air pollution. The refineries emit methane, $\mathrm{CO} 2, \mathrm{SO} 2$, nitrous oxide and aerosols which are toxic and can cause health issues resulted in increased cases of asthma and heart attacks [33].

2) Water pollution. Oil and gas industry consume a lot of water, and the wastewater produced are very difficult to treat which causes water contamination [26].

3) Acidification. The main cause of acid rain is the emission of $\mathrm{SO} 2, \mathrm{NO} 2$ etc in the atmosphere by the oil and gas industry [34]. It was revealed that about $75 \%$ of lakes and $50 \%$ of steams in USA reportedly had $\mathrm{pH}$ level lower than 5 [35], and about 14,000 lakes in eastern Canada were also acidic. The lower $\mathrm{pH}$ level kills the fish's, snails and other intolerant organisms. It is calculated [19] that about half of the atmospheric acids falls back to earth in the form or rain, ice and snow which release all the fertility properties from the soil making it unfit for any kind of cultivation.

4) Accumulation of toxicity. The oil spills have tremendous effect on the aquatic ecosystems [36]. The marine organisms absorb toxic oils which could be lethal to themselves after longer time and for higher organisms in the food chain.

The next task is to identify and quantify the hazards and risks, as well as their relationship with possible incidents/accidents.

\section{EVENTS AND RISKS IDENTIFICATION}

The term hazard or threat $(H)$ [37] is defined as an event or a type of circumstances that possesses threat to the environment, health or human life. Further states that happen and could cause damage to the environment and/or the infrastructure is known as Accident $(A)$. One of the things that follow the accident/incident are the environmental Impacts $(I)$ such as air pollution, water pollution, land pollution etc. These are the repercussions of the hazard/threat which is followed by accident/incident. The Effects $(E)$ of the impact determine the severity of the repercussions caused by the accidents to the environment.It is important to determine the fair share of the accidents that has happened within the oil and gas industry so has to get an abstract idea of what might be the risk that a particular type of accident could happen at all and how much impact does that cause environment.M. Christou and M. Kostantinidou [20], and A. Necci et al. [37] use data from World Offshore Accident Database (WOAD) and other to research the accident statistics in oil and gas industry. As major accidents are classified fire, explosion, and oil spills. There are also main Hazards/threats $(H)$ identified: War $\left(H_{1}\right)$, Seismic activities $\left(H_{2}\right)$, Geological structure $\left(H_{3}\right)$, Terrorism $\left(H_{4}\right)$, Collisions $\left(H_{5}\right)$ and Mechanical failures $\left(H_{6}\right)$.

The war effects on oil and gas industry footprint were analyzed by J. Pitkin [38] and G. Luciani [39]. According to B. Fattouh [40] the terrorism is one of the major threats to the oil and gas industry, although M. Torhaug [41] states that of all the terrorist activities in the world within the period 19681999 , only $2 \%$ of the total attacks were waged towards petroleum industry. According to K. Ashild and L.Brynjar [42] there were 262 accidents caused by terrorist activities during this period as per international terrorism comprehensive database (ITERATE). F. Steinhausler et al. [43] considers supply chain stages of the possible terrorist attacks in the oil and gas industry. These are rigs, marine transportation, distribution system and refineries. Saudi Arabia [44] is one of the leading producers of oil, and in security measures of infrastructure are occupied over 30000 people at any given time.

According to AGI [45] and G. R. Foulger et al. [46] the pressure change could potentially cause manmade earthquakes. An earthquake in 2011 reported a massive 5.8 magnitude in Oklahoma which was the strongest manmade seismic activity recorded due to hydraulic fracturing. According to Zurich Risk Engineering [47] hydraulic fracturing and wastewater disposal in oil and gas industry are the most common cause of man induced earthquakes.

Collision is a very common occurrence in oil and gas industry either man-made or due to mechanical failures. M. Christou et al. [20] taken an example of a case study conducted which states that accidents like slip/trips/falls are very common in oil and gas rigs, despite of it that $80 \%$ of the rig have safety measures to prevent them. However, these 
accidents have lower contributed to the overall share of the environmental impact.

Mechanical failures [48] could occur due to vary factors such as stresses, pressure, fracture, failures, and impacts. Mechanical failures would include failure of valves, blow out preventers, fracture or fatigue of pipelines and seal assembly failure and is the result of major safety, health, and environmental consequences. A. Saddek [48] reported that according to a survey conducted among several rig operators in the Gulf of Mexico, it was revealed that $30 \%$ to $50 \%$ of the pressure valves have failed. It was assessed that around $18 \%$ of wells worldwide have weakness or even seal assembly failures in High-Pressure High-Temperature completion.

M. Alkhaldi et al. [49] analyzed accidents in Bahrain oil and gas industry. It is mentioned [49] that most of accidents could appear in various levels of the supply chain operations, and the risks were higher than general industries. D. Frommer and A. Torem [36] and Schneider et al. [5] consider that most accidents and incidents takes place in the drilling and production process, and the environmental impact on plants, aquatic organisms, marine animals, ecosystems, and human health is significant.

According to M. J. Hoover [50] from the data's collected over the years it can be considered that the industry is more prone to the risk of explosion, fire, and leak than any other accidents. According to SynergenOG [51] the main purpose of learning from the past accidents is to understand the risks and alternative scenarios.

The mentioned above allows the creation of a causal chain of events: Hazards / threats $(H)$, Accidents / incidents $(A)$ and Effects / footprint on environment $(E)$. Each event has its own risks $(R)$ and significance of impact. Each of the events in the hazard / threats group may correspond to a different set of accidents / incidents elements. Each of the accidents has a specific Impact $(I)$ and it produces different Effects on the environment $(E)$.

An important issue is the quantification [52] of the significance of Risks $(R)$ and Impacts $(I)$. Some events have binary values of the significance of risks and impacts, while the Likert 5-point scale (very low, low, medium, high, very high) is used to assess others. Data for quantification of risks and impacts are mined from public registers and databases. For example, data on mechanical failures are obtained from the Bureau of Safety and Environmental Enforcement (BSEE) [53], but data on terrorism impact are gathered from the reports on terrorism around the world from the Center for Contemporary Conflict [41], etc.

Different methods exist to assess environmental impact and effects of potential accidents. Some popular methods will be discussed later to identify most common set of environmental effects assessed.

\section{EnVIRonmental ImPact Assessment Methods}

C. Stevens [54], mentions different types of landscape for impact assessment, however leading is sustainability. J. Pope et al. [55], states that the concept of sustainability development is based on the concept of Triple Bottom Line (TBL) (business, society, and environment). For sustainability development assessment and modeling different methods are used [56]. However, in this case, we will focus on only one pillar, i.e., impacts on the environment.

J. Glasson et al. [57], describes Environmental Impact Assessment (EIA) as a technique in which the environmental effects and related information's are collected by the source and then taken to the planning authority and decided whether to move ahead with the development. D. R. Turner and L. Canter [58] state that it is important to comply with the National Environmental Policy Act (NEPA) and by doing so addressing the common and the most potential environmental consequences (usage of land,quality of air, usage of water,quality of soil and its biology,cultural resources,socioeconomics, public health and occupational health, accidents,noise scale,aesthetics,utility management,waste management and environmental justice). J. Pope et al. [55] and P. Ksiezak et al. [59] describe the environmental pillar as a dimension which relies on the standard of living. According to O. A. Amos et al. [60] the main goal of the environmental pillar is to reduce the ecological footprint, emission etc. while retaining the efficient usage of the environmental and energy resources. L. MunozPascual et al. [61] and P. Ksiezak et al. [59] mention that the organization should aim at processing long-range trends and tactical methods which could in-corporate quality of air, water, consumption of energy and natural resources, toxic wastes and wildlife and marine species.

N. Gorlenko et al. [62] states that while doing the impact assessment in oil and gas production industries, the natural indicators should always be considered to get the most efficient results. F. Vanclay [63] mentions that there are 142 types and more of impact assessments mostly which are referred to mining, dams, and costal developments.

There are six environmental impacts assessment methods which are consistently used in energy sectors especially oil and gas industries:

1) Ecological Assessment. According to U.S. Environmental Protection Agency (EPA) [64] ecological assessment is basically a document accounting to the portion which shows the sustainability of the planet earth that is being used by the human economies. This applies to massive global industries which consumes large amount of energy into production and operation.A. K. Meena and T. K. Yadav [65] describe ecological assessment as an accounting system that is used to measure the human demand on the nature. The author further states that the ecological footprint is one of the uses and manages resources and sustainability of organizations, regions, industrials sectors etc. by providing a vital role towards the sustainability assessment.R. Itten et al. [66] suggests what factors need to be considered while calculating the ecological assessment. That being air, water, radioactive contamination, toxic hydrocarbons, acidification etc. The set of effects measured for ecological assessment are following - quality of air, land and water, leak, PH level 
of rainwater, solid wastes, and toxicity levels. This approach was used by British Petroleum (BP) in 2019 [67] to address the sustainability issues by valuing that there was no damage to the environment maintaining the maximum performance. Shell [68] designed their yearly sustainability assessment method. The assessment was done to reduce the airborne pollutants that occur during the supply chain processes of the company. One of the limitations that arise according to methods is that the testing/sampling of the subject might take long time.

2) Carbon Footprint Assessment. D. Pandey et al. [69] mentions different issues caused on earth due to carbon emission from industries, transportations etc., like increase in global temperature, change of whether etc. Especially in oil and gas industry where the emission of carbon into the air is inevitable. P. Bhatia [70] discussed the global harmonized standards with the main objective towards measuring carbon footprint across the value chain that being upstream, mid-stream and downstream. J. M. Hudson et al. [71] analyzed how to quantify, investigate, and propose new methods towards reducing the carbon footprint. The set of effects measured for carbon footprint is following - direct carbon emission ( $\mathrm{CO} 2, \mathrm{CH} 4$ etc.), carbon energy intensity and third-party carbon emission. In 2018, Saudi Aramco provided analysis Enviro News [72] how to reduce carbon emission. Similar activities were done by Exxon Mobil [73] in Carbon Disclosure Project (CDP).

3) Environmental Life Cycle Assessment. S. Joshi [74] described Life Cycle Assessment (LCA) as the tool that is used towards assessing the environmental impacts on every stage of the business process. There were five stages that involve extraction of raw materials, manufacturing and processing, transportation, retail and finally waste disposal. According to IFU [75] and O. Jolliet et al. [76] the LCA is carried out in four steps in total (goal and scope, inventory, impact assessment and interpretation). H. Baumann and T. Rydberg [77] used this method by considering global warming, toxic chemical dispersion, waste disposal, electricity use, acidification etc. The set of effects measured for LCA in oil and gas industry are following - greenhouse gases, chemical dispersion, waste disposal, acidification, recycle and reusability, and heat. In 2019 Chevron [78] and Shell [68] indulged waste disposal as one of the parameters for the assessments towards environmental management.

4) Water Footprint Assessment. According to A. Y. Hoekstra et al. [79] water footprint is an environmental impact assessment technique that is used as a global standard when it comes to measuring the pollutants and the contamination levels present in water bodies. According to WaterCalculator [80], it is estimated that the energy production industry in USA used a total of $72 \%$ of the water sources were used heavily from fresh water sources like lakes, rivers etc. Most of this water is used from cooling systems which could impact the aquatic ecosystem. The set of effects measured for water footprint in oil and gas industry are following - water intensity rate and dispersion rate, water quality and availability.

5) Planetary Boundary Assessment. According to W. Steffen et al. [81] the main aim of planetary boundary is to provide a safe space for operation based on important processes based in ecological factors which would regulate the boundaries of environmental framework. F. Biermann and R. E. Kim [82] describe planetary boundaries as a "safe operating space" for the humanity. J. Rockstrom et al. [83] identified planetary boundaries and has provided quantification for better margin of scale and understanding. The identified planetary boundaries are as follows (carbon emission, oceanic acidification, stratospheric ozone, biochemical nitrogen and phosphorous cycle, global freshwater use, land system change, loss of biological diversity, chemical pollution, and atmospheric aerosol loading). Generally, the set of effects measured for planetary boundary in oil and gas industry are following - carbon emission, acidification, water, and land usage.

The analysis of the above methods makes it possible to determine a measurable set of basic parameters for the assessment of environmental Effects (E), which must not exceed certain thresholds (see Table I).

I. The set of Hazard/Accident/Impact/Effect events

\begin{tabular}{|c|c|c|c|}
\hline $\begin{array}{c}\text { Hazard } \\
\left(H_{i}\right)\end{array}$ & $\begin{array}{l}\text { Accident } \\
\left(A_{j}\right)\end{array}$ & $\begin{array}{c}\text { Environmental } \\
\text { impacts }\left(I_{k}\right)\end{array}$ & $\begin{array}{l}\text { Environmental } \\
\text { effects }\left(E_{n}\right)\end{array}$ \\
\hline \multirow{2}{*}{$\operatorname{War}\left(H_{1}\right)$} & $\begin{array}{l}\text { Explosion } \\
\left(A_{1}\right)\end{array}$ & Air pollution $\left(I_{1}\right)$ & \multirow{2}{*}{$\begin{array}{l}\text { Chemical } \\
\text { composition of } \\
\operatorname{air}\left(E_{1}\right)\end{array}$} \\
\hline & Fire $\left(A_{2}\right)$ & $\begin{array}{c}\text { Marine life } \\
\text { endangerment }\left(I_{2}\right)\end{array}$ & \\
\hline \multirow{3}{*}{$\begin{array}{l}\text { Seismic } \\
\text { activities } \\
\quad\left(\mathrm{H}_{2}\right)\end{array}$} & \multirow{2}{*}{$\operatorname{Leak}\left(A_{3}\right)$} & Land pollution $\left(I_{3}\right)$ & \multirow{2}{*}{$\begin{array}{c}\mathrm{pH} \text { level of } \\
\text { rainwater }\left(E_{2}\right)\end{array}$} \\
\hline & & Deforestation $\left(I_{4}\right)$ & \\
\hline & \multirow{2}{*}{$\begin{array}{l}\text { Bio attack } \\
\quad\left(A_{4}\right)\end{array}$} & Acid rain $\left(I_{5}\right)$ & \multirow{2}{*}{$\begin{array}{c}\text { Physical } \\
\text { changes to the } \\
\text { habitat }\left(E_{3}\right)\end{array}$} \\
\hline \multirow{3}{*}{$\begin{array}{l}\text { Geological } \\
\text { structure } \\
\left(\mathrm{H}_{3}\right)\end{array}$} & & $\begin{array}{c}\text { Underground water } \\
\text { pollution }\left(I_{6}\right)\end{array}$ & \\
\hline & $\begin{array}{c}\text { Earthquake } \\
\left(A_{5}\right)\end{array}$ & Water pollution $\left(I_{7}\right)$ & $\begin{array}{l}\text { Waste disposal } \\
\left(E_{4}\right)\end{array}$ \\
\hline & \multirow{2}{*}{$\begin{array}{l}\text { Rig failure } \\
\quad\left(A_{6}\right)\end{array}$} & $\begin{array}{l}\text { Effects on flora and } \\
\text { fauna }\left(I_{8}\right)\end{array}$ & \multirow{2}{*}{$\begin{array}{c}\text { Water } \\
\text { pollution }\left(E_{5}\right)\end{array}$} \\
\hline \multirow{3}{*}{$\begin{array}{l}\text { Terrorism } \\
\qquad\left(H_{4}\right)\end{array}$} & & $\begin{array}{c}\text { Uranium depletion } \\
\left(I_{9}\right)\end{array}$ & \\
\hline & $\begin{array}{c}\text { Welding } \\
\text { failure }\left(A_{7}\right) \\
\end{array}$ & $\begin{array}{c}\text { Chemical defoliants } \\
\left(I_{10}\right)\end{array}$ & \multirow{2}{*}{$\begin{array}{c}\text { Carbon } \\
\text { footprint }\left(E_{6}\right)\end{array}$} \\
\hline & $\begin{array}{l}\text { Trip/Slip } \\
\left(A_{8}\right)\end{array}$ & Landslide $\left(I_{11}\right)$ & \\
\hline \multirow{3}{*}{$\begin{array}{l}\text { Collisions } \\
\qquad\left(H_{5}\right)\end{array}$} & Pipe failure & $\begin{array}{l}\text { Land deformation } \\
\left(I_{12}\right)\end{array}$ & \multirow{3}{*}{$\begin{array}{l}\text { Land usage } \\
\qquad\left(E_{7}\right)\end{array}$} \\
\hline & & Liquefaction $\left(I_{13}\right)$ & \\
\hline & \multirow{2}{*}{$\begin{array}{l}\text { Design } \\
\text { failure } \\
\left(A_{10}\right) \\
\end{array}$} & $\begin{array}{c}\text { Greenhouse effect } \\
\left(I_{14}\right) \\
\end{array}$ & \\
\hline \multirow{3}{*}{$\begin{array}{c}\text { Mechanical } \\
\text { failures } \\
\left(H_{6}\right)\end{array}$} & & Gas leak $\left(I_{15}\right)$ & \multirow{3}{*}{$\begin{array}{l}\text { Toxicity level } \\
\left(E_{8}\right)\end{array}$} \\
\hline & \multirow{2}{*}{$\begin{array}{l}\text { Fracture } \\
\left(A_{11}\right)\end{array}$} & $\begin{array}{c}\text { Wildlife } \\
\text { endangerment }\left(I_{16}\right)\end{array}$ & \\
\hline & & Oil spillage $\left(I_{17}\right)$ & \\
\hline
\end{tabular}

If Hazard $(H)$ happens, it results in multiple Accidents $(A)$ 
having a set of certain Impacts $(I)$. In turn, each of these Impacts $(I)$ has a greater or lesser impact on the environment and creates a set of lasting Effects $(E)$. Further assessment comprises only eight long lasting Effects $(E)$, which have been identified in a previous analysis as being most used in various environmental impact assessment methods mentioned above. This makes it possible to derive a causal tree $(S)$ :

$$
S=\langle H, A, I, E\rangle
$$

Recognized relationships among events are specified in Table II to Table IV.

II. Hazards $\left(H_{i}, \underset{i=1,6}{\longrightarrow}\right)$ and accidents $\left(A_{j}, \underset{j=1,11}{\longrightarrow}\right)$ relationships

\begin{tabular}{|c|l|l|l|l|l|l|l|l|l|l|l|}
\hline & 1 & 2 & 3 & 4 & 5 & 6 & 7 & 8 & 9 & 10 & 11 \\
\hline 1 & + & + & + & + & & & & & & & \\
\hline 2 & & & & & + & & & & & & \\
\hline 3 & + & + & + & & & & & & & & \\
\hline 4 & + & + & + & & & & & & & & \\
\hline 5 & & + & & & & + & + & + & & & \\
\hline 6 & & & & & & & & & + & + & + \\
\hline
\end{tabular}

III. Impacts $\left(I_{k}, \underset{k=1,17}{\longrightarrow}\right)$ and accidents $\left(A_{j}, \underset{j=1,11}{\longrightarrow}\right)$ relationships

\begin{tabular}{|c|c|c|c|c|c|c|c|c|c|c|c|}
\hline & 1 & 2 & 3 & 4 & 5 & 6 & 7 & 8 & 9 & 10 & 11 \\
\hline 1 & + & + & & & & + & + & & & & + \\
\hline 2 & + & & + & & & & & & + & & + \\
\hline 3 & + & & & & & & & & & & \\
\hline 4 & & + & & & & & & & & & \\
\hline 5 & & + & & & & & & & & & \\
\hline 6 & & & + & & & & & & & & \\
\hline 7 & & & + & & & + & + & + & + & + & + \\
\hline 8 & & & + & & & & & & & & \\
\hline 9 & & & & + & & & & & & & \\
\hline 10 & & & & + & & & & & & & \\
\hline 11 & & & & & + & & & & & & \\
\hline 12 & & & & & + & & & & & & \\
\hline 13 & & & & & + & & & & & & \\
\hline 14 & + & & & & & & & & & & \\
\hline 15 & & & + & & & & + & & + & & + \\
\hline 16 & & + & & & & & & & & & \\
\hline 17 & & & & & & & & & & + & + \\
\hline
\end{tabular}

\begin{tabular}{|c|c|c|c|c|c|c|c|c|}
\hline \multicolumn{4}{|c|}{ IV. Impacts $\left(I_{k}, \underset{k=1,17}{\longrightarrow}\right)$} & \multicolumn{5}{|c|}{$\begin{array}{l}\text { and environmental effects }\left(E_{n}, \underset{n=1,8}{\longrightarrow}\right) \\
\text { relationships }\end{array}$} \\
\hline & 1 & 2 & 3 & 4 & 5 & 6 & 7 & 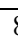 \\
\hline 1 & + & & & & & + & & \\
\hline 2 & & & + & & & & & \\
\hline 3 & & & & & & & + & \\
\hline 4 & & & + & & & & & \\
\hline 5 & & + & & & & & & \\
\hline
\end{tabular}

\begin{tabular}{|c|l|l|l|l|l|l|l|l|}
\hline 6 & & & & + & + & & & \\
\hline 7 & & & & & + & & & \\
\hline 8 & & & + & & & & & \\
\hline 9 & & & & & & & & + \\
\hline 10 & & & & & & & & + \\
\hline 11 & & & & & & & + & \\
\hline 12 & & & & & & & + & \\
\hline 13 & & & & & & & + & \\
\hline 14 & + & & & & & & & \\
\hline 15 & + & & & & & & & \\
\hline 16 & & & + & & & & & \\
\hline 17 & & & & + & + & & & \\
\hline
\end{tabular}

In the oil and gas industry, it is very important to assess in a timely and interactive manner the potential risks of various hazards, both when designing new and operating existing supply chains.

\section{V.RISK ASSESSMENT METHODS IN OIL AND GAS INDUSTRY}

Oil and gas industry is vulnerable to risk factors. The range of risk hazards vary from human errors to natural disasters. According to R. Aetdinova et al. [84] risk assessment modeling is used to measure the risks related with environmental and socio-economic factors with variety of acceptable criteria. Risk assessment methodology guidelines [85] give a descriptive step in the process that is required to develop a risk scenario. The first step is identification of the risk, next is description of the risk which includes event description and specification of different environmental conditions. Likelihood assessment is one of the next steps for the time-period when the risk occurred. Consequences and impact assessment of the scenario follow before designing the treatment plan and mitigation measures.

An important issue is the forecasting of risks and impacts, which should ensure good transparency and efficiency, otherwise the management process becomes problematic, but risk mitigation may be delayed. This means that operational risk assessment should not be performed by specially educated specialists in mathematics, chemistry, and environment protection, but by the company's managers. Thus, operational risk assessment methods cannot be labor intensive and complicated. Both qualitative and quantitative risk assessment methods may be used. There are the various methods used for performing risk assessment in oil and gas supply chains:

1) Risk Screening Process. J. L. Hawksley [8] states that risk screening process is a method where the varying range of risks is considered, and ranking is done according to its significance. The method was used by Shell to identify the range of risks happening within the offshore rig accidents and to design risks assessment matrix aimed to risks importance recognition.

2) Risk Evaluation Matrix. The method was used by BP [9] to identify the consequences on environmental, health, safety, and non-financial impacts according to the severity 
level of the event. The matrix consists of tables of thresholds and mitigation tasks, hazards identification, impact consequences and probability of risks. The advantage of using Risk Evaluation Matrix is that this method has a good production pattern which lets the user determine the risk size and helps in better decision making with various numbers of alternatives. Main disadvantage of this method is that assessment asks for long time and should be done by experienced professionals.

3) Hazard Environment and Safety (HES) Risk Management Process. HES Risk Management Process [10] is a structured assessment method providing a set of defined responsibilities and scope for all the enterprise. Chevron used HES Risk Management Process for better understanding of the local and global risks. The risk included occupational, toxic, explosive, thermal and flash fire. Qualitative and quantitative assessments were done. The advantage of using HES Risk Management Process is advanced structure of decision making. There is a general point of view, implication in the form of life cycle and from the stakeholder point of view. The disadvantage being is time consuming verification and peer review benchmarking by experts.

4) Hazard and Operability Study (HAZOP). The method [11] is widely used in USA and EU to identify the potential hazards and operational problems focusing on the solution. The HAZOP technique follows three steps the complete description of the events or process, examining the complete part of the process with precision and identifying of the problems and recognition the potential risks of causing hazards. The main disadvantage being that HAZOP requires a technical input from experienced consultants for evaluating the results.

5) Bayesian Networks. Bayesian Network (BN) [86] shows the probabilistic relationship among random variables and influence relationships created based on the combined dependencies. One of the advantages that $\mathrm{BN}$ has over other risk assessment methods is regarding interactivity and performance of assessment. In 2019, L. Kaikkonen et al. [87] identified 497 articles that have been published in the last 15 years related to Bayesian networks use for environmental risk assessment, while 72 applications have been analyzed in detail. In most applications [87], the environmental risk assessment started halfway, i.e., with existing impacts, but the causes of these impacts were shyly circumvented. Practically, the risks were analyzed when the damage had already occurred. The oil and gas industry are a specific industry whose existence a priori poses a threat to the environment. Halfway through analyzing the environmental risks in this sector will not be enough, as it is important to start with the hazards, potential risks and their consequences that will have an impact and lasting effects on the environment. S. M. Deyab et al. [88] argue about $\mathrm{BN}$ being used for probabilistic analysis of the risks in the oil and gas industry.

\section{WHY BAYESIAN NETWORKS?}

In 1764 Bayes T. issued An Essay Toward Solving a Problem in the Doctrine of Chances [89] where explained conditional relationships between two events, where one event $x_{2}$ affects $x_{1}$ :

$$
\mathrm{P}\left(x_{1} \mid x_{2}\right)=\left(P\left(x_{2} \mid x_{1}\right) * P\left(x_{1}\right)\right) / P\left(x_{2}\right)
$$

where $\mathrm{P}\left(x_{1} \mid x_{2}\right)$ - conditional probability or likelihood of event $x_{1}$ occurring given that $x_{2}$ is evident, $P\left(x_{2} \mid x_{1}\right)$ conditional probability or likelihood of event $x_{2}$ occurring given that $x_{1}$ is evident, but $P\left(x_{1}\right)$ and $P\left(x_{2}\right)$ - marginal probabilities of observing $x_{1}$ and $x_{2}$ respectively.

There is a causal and probabilistic dependency between two random variables, when the two corresponding nodes in the graph are connected by a directed edge (see Fig. 1). The edge directed from a node $x_{2}$ to $x_{1}$ indicates that the random variable $x_{2}$ causes the random variable $x_{1}$, and the edge shows a static causal probabilistic dependence.

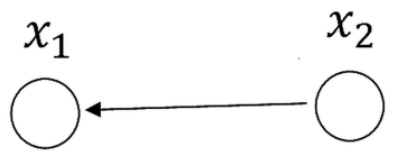

Fig. 1 Graphical interpretation of two nodes Bayesian network

Each Bayesian network can be thought of as a set of paired nodes, where each event can be associated with one or more other events.

A Bayesian network encodes a unique common probability distribution that can be easily computed using the chain rule [90]. Joint probability of mentioned network of two nodes $x_{1}$ and $x_{2}$ is following:

$$
P\left(x_{1}, x_{2}\right)=P\left(x_{2} \mid x_{1}\right) * P\left(x_{1}\right)=P\left(x_{1} \mid x_{2}\right) * P\left(x_{2}\right)
$$

where $P\left(x_{1}, x_{2}\right)$ - joint probability of both events and product rule.

The Bayesian network allows the system to be specified and studied as a set of interrelated and interacting elements. Knowing the result of the impact, it is possible to determine the guilty element with appropriate probability. The use of BN is useful in systems diagnostics, but since the classic BN does not allow feedback, those may not be the best choice for describing system regulation and control tasks.

Successful application of BN depends on the design of a proper causal network and quantification of node values. The results of the modeling depend on the professionalism of the experts and the quality of the available data. In addition, BN networks are convenient enough to use machine learning methods to determine the values of nodes. This means that expert knowledge is used to initialize the probability propagation network, but further training and tuning of the BN network model can follow.

Of course, the calculation of probability propagation in acyclic graphs in the case of real systems research requires appropriate computational resources, so the full application of 
Bayesian ideas became popular in the late 20th century. Besides, BNs can be used successfully for interactive modeling of impacts and risks, providing an efficient and transparent representation of the relationship between events.

BN networks are used, for example, to analyze the impact of management on the quality of production [91], Web usability and services providing [92], customer satisfaction research [93], healthcare organization evaluation in hospitals [94], Covid-19 prevalence, mortality and infection spreading risks assessment [95], [96] etc.The oil and gas industry is no exception.

\section{BAYESIAN NETWORK USE FOR RISKS MODELING IN OIL AND GAS INDUSTRY}

The Bayesian acyclic network created is a risks probability distribution model that is designed for hazards and related accidents environmental impact analysis. The hazards/accidents/impacts/effects assigned to the model would let the user to have a clear idea of the effects that would be the resultant of the hazards/accidents that would impact the environment and are caused by the oil and gas industry with appropriate probability or risk.

The approach proposed by the authors is based on acyclic $\mathrm{BN}$, but does not consider dynamic BN. However, even in this case, stability problems may arise, that is, how stable the interactions between each factor and the factors are. Quantification results are based on expert opinions and experience data. With the emergence of precedents, the structure of $\mathrm{BN}$ will have to change, but changes in relationships are not complicated. It is possible to create a stability matrix, but in this case it is not necessary, because the events and impacts to be assessed in the oil and gas industry are not large and rapidly changing data, where unforeseen changes in one event can immediately destroy the stability of the risk assessment network.

The main function of the model is to get a grasp of the idea of the outcome of a certain hazards that happened in the oil and gas industry. As they happened over a span of certain time frame, they resultant data is taken, converted into the values that is suitable to be fed into the model and the main evidence node is set to 'Yes' and the result is observed. The feature of $\mathrm{BN}$ and its ability to easily accumulate and make use and combine the data and give the best results possible even with multiple outputs makes it probably one of the easier models to use. The main purpose of the model is to forecast the chances of events that could possibly cause or lead to the environmental footprint. Able to identify these events prior to its happening would give an advantage as it could be able to know the effects that could possibly impact the environment and to devise a sustainability assessment method to counter them. It is possible to check one or more hazards or scenarios at the same time and see the outcome as it is supposed to be.

Each hazard that happens has own or common related accidents that follow down the line (see Table I to Table IV). The model already has pre-set accidents related to the hazards which have been set according to the research and these accidents are most likely to happen during any of these hazards. For each hazard $H_{i}$ it is possible to design an appropriate $\mathrm{BN}$ that characterizes hazard impacts and effects on the environment (see Fig. 2 to Fig. 7).

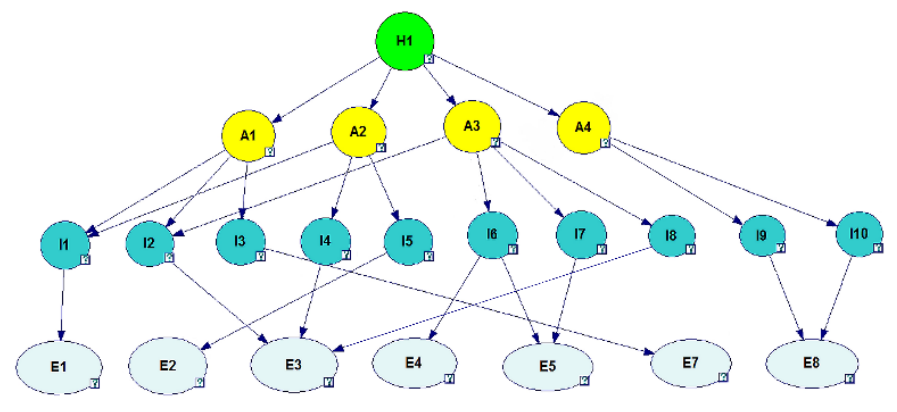

Fig. 2 War $\left(H_{1}\right)$ event graph

Hazard $\left(H_{1}\right) \mathrm{BN}$ analytical specification is as follows:

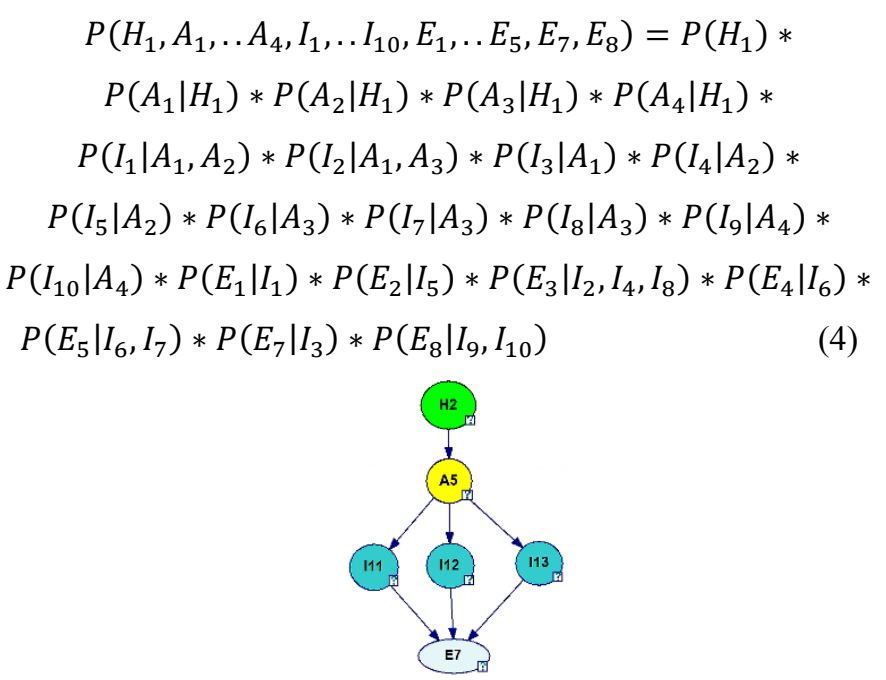

Fig. 3 Seismic activities $\left(H_{2}\right)$ event graph

Hazard $\left(\mathrm{H}_{2}\right) \mathrm{BN}$ analytical specification is as follows:

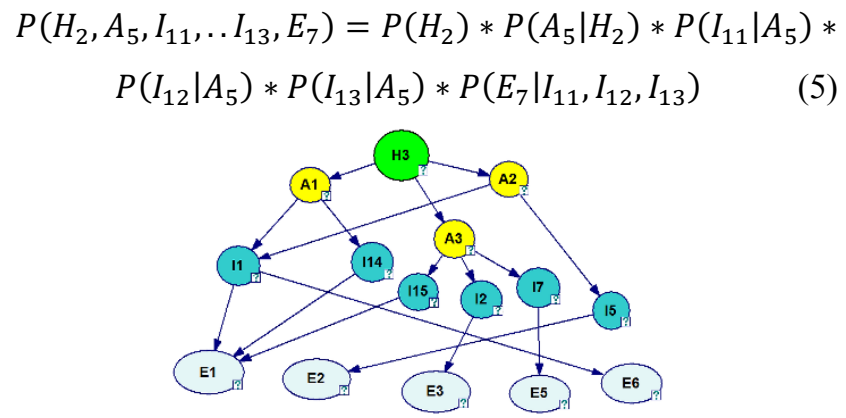

Fig. 4 Geological structure $\left(H_{3}\right)$ event graph

Hazard $\left(H_{3}\right) \mathrm{BN}$ analytical specification is as follows: 


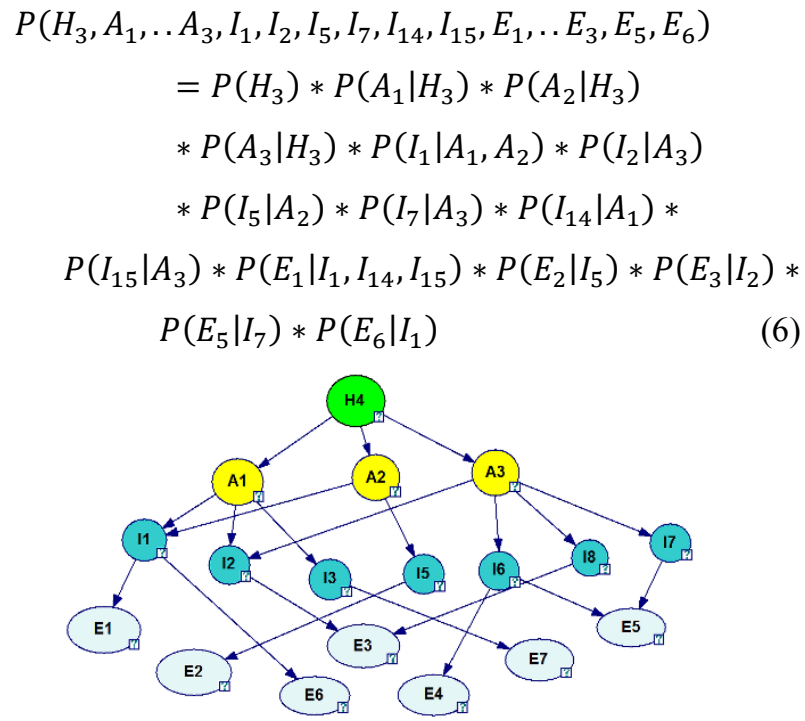

Fig. 5 Terrorism $\left(H_{4}\right)$ event graph

Hazard $\left(H_{4}\right) \mathrm{BN}$ analytical specification is as follows:

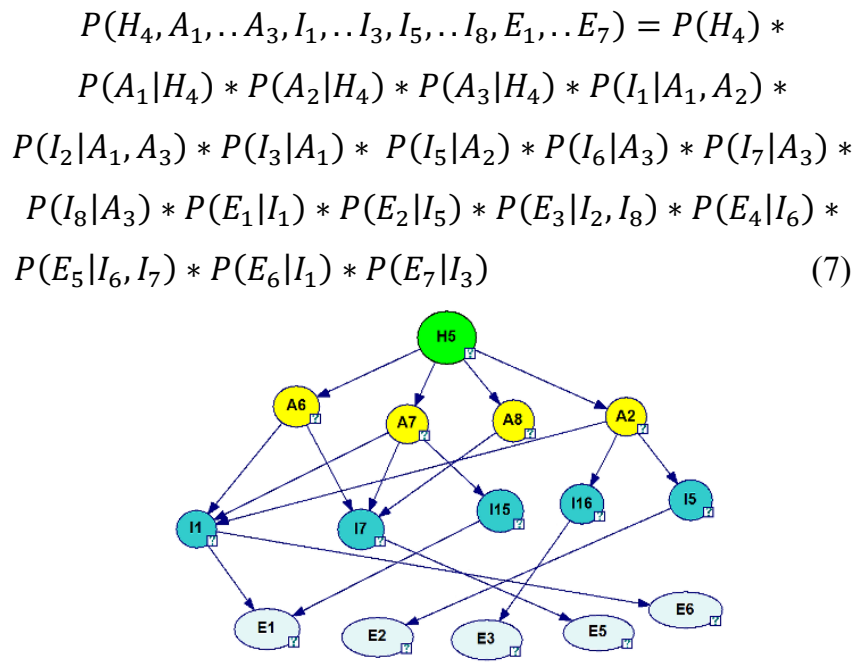

Fig. 6 Collisions $\left(H_{5}\right)$ event graph

Hazard $\left(H_{5}\right)$ BN analytical specification is as follows:

$$
\begin{aligned}
& \quad P\left(H_{5}, A_{2}, A_{6}, . A_{8}, I_{1}, I_{5}, I_{7}, I_{15}, I_{16}, E_{1}, \ldots E_{3}, E_{5}, E_{6}\right)= \\
& P\left(H_{5}\right) * P\left(A_{2} \mid H_{5}\right) * P\left(A_{6} \mid H_{5}\right) * P\left(A_{7} \mid H_{5}\right) * P\left(A_{8} \mid H_{5}\right) * \\
& P\left(I_{1} \mid A_{2}, A_{6}, A_{7}\right) * P\left(I_{5} \mid A_{2}\right) * P\left(I_{7} \mid A_{6}, A_{7}, A_{8}\right) * P\left(I_{15} \mid A_{7}\right) * \\
& P\left(I_{16} \mid A_{2}\right) * P\left(E_{1} \mid I_{1}, I_{15}\right) * P\left(E_{2} \mid I_{5}\right) * P\left(E_{3} \mid I_{16}\right) * P\left(E_{5} \mid I_{7}\right) * \\
& P\left(E_{6} \mid I_{1}\right)
\end{aligned}
$$

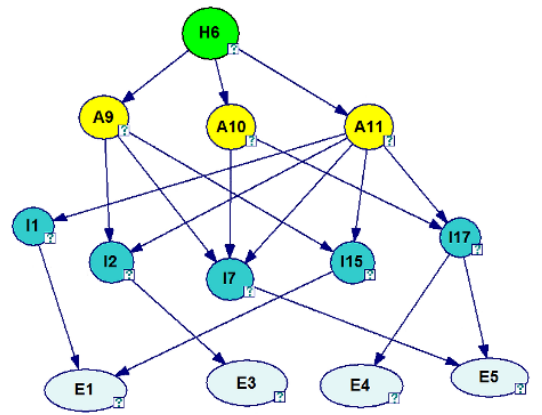

Fig. 7 Mechanical failures $\left(H_{6}\right)$ event graph

Hazard $(H) \mathrm{BN}$ analytical specification is as follows:

$$
\begin{aligned}
& P\left(H_{6}, A_{9}, \ldots A_{11}, I_{1}, I_{2}, I_{7}, I_{15}, I_{17}, E_{1}, E_{3}, \ldots E_{5}\right)=P\left(H_{6}\right) * \\
& P\left(A_{9} \mid H_{6}\right) * P\left(A_{10} \mid H_{6}\right) * P\left(A_{11} \mid H_{6}\right) * P\left(I_{1} \mid A_{11}\right) * \\
& P\left(I_{2} \mid A_{9}, A_{11}\right) * P\left(I_{7} \mid A_{9}, A_{10}, A_{11}\right) * P\left(I_{15} \mid A_{9}, A_{11}\right) * \\
& P\left(I_{17} \mid A_{10}, A_{11}\right) * P\left(E_{1} \mid I_{1}, I_{15}\right) * P\left(E_{3} \mid I_{2}\right) * P\left(E_{4} \mid I_{17}\right) * \\
& P\left(E_{5} \mid I_{7}, I_{17}\right)
\end{aligned}
$$

The network (see Fig. 8) describes the propagation of event risks $R$, which is characterized by probability $P$. In this case, to respect the traditions of analytical specification, the notation $P$ is used instead of $R$, but it should be understood that $P=R$.

The common supply chain 4-level risk model (see Fig. 8) describes the potential effects of all events and multiple hazards that produce effects on the environment. The software used for designing and running the model is GeNIe Modeler [97], [98].

In this case, an abbreviated formula (10) is applied, because it would not be reasonable to use the full analytical risk specification due to high complexity and low transparency. It demonstrates why it is desirable to use automated modeling tools, because graphical notation also is not convenient enough (see Fig. 8) which can lead to specification errors:

$$
P(H)=P\left(H_{1}, H_{2}, \ldots H_{6}\right)
$$

The initial values of the model are determined based on previous data analysis. However, the model can be easily tuned and adapted for use in specific supply chain conditions. The final effects are visible when the evidence is set on the event nodes. The evidence feature can be assigned to any event or set of events. 


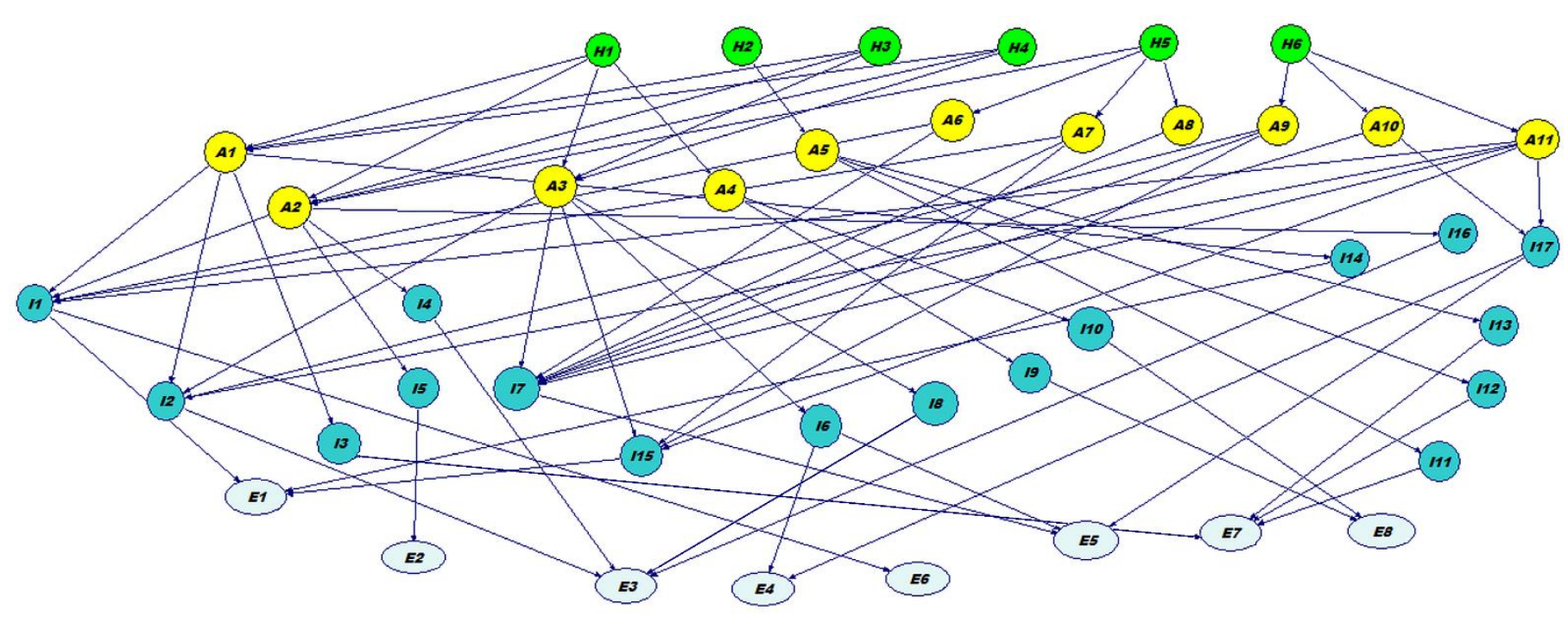

Fig. 8 Total risks $(H)$ event graph

The Bayesian model provides risks probability propagation. This makes it possible to check different scenarios, in particular during operational risk management, in order to answer the question, what will happen if? Even more important, however, is the reverse use of the Bayesian model to answer the question, what is the reason if specific effects on the environment have been identified? The modeling results can be used to prepare a supply chain environmental risk assessment report.

The verification of the $\mathrm{BN}$ model was performed on the limit values, that is, if there is no hazard, then there are no effects on the environment. Changes in the risks of each hazard left changes in the effects on the environment. With increasing threats and the likelihood of accidents also increased effects. The results of the $\mathrm{BN}$ model running on BayesFusion [98] environment was compared with the results of analytical calculations.

Model validation was not so simple, as the approach proposed by the authors differs from the methods currently used in the oil and gas industry [9]-[11]. The validation results showed an appropriate correlation, but an exact comparison was not possible. The risk assessment model proposed by the authors shows a trend rather than an accurate result. The second validation option was to assess the usefulness of the model by listening to experts. The sample of respondents was too small and did not allow for a statistically reliable assessment. However, the overall view was in line with the normal distribution of estimates at $95 \%$ confidence after the Kolmogorov-Smirnov nonparametric test. Respondents considered that the specific BN model was useful for environmental risks preliminary assessment and positively assessed the model's interactivity and transparency. It was emphasized that the model is more appropriate for the upstream and midstream segments of the supply chain, but less applicable to the downstream segment.

The authors' self-assessment of the sustainability of the BN risk model was performed using the Integrated Acceptance and Sustainability Assessment Model (IASAM) [56]. A rating of 0.78 skypes means that the technology is sustainable and usable, but investments are required for its further development.

\section{VIII.CONCLUSION}

One of the key sectors of today's economy is the oil and gas industry, where ongoing production processes and supply chains a priori pose threats to the environment.

Impact on nature creates lasting effects that can be reduced by timely identification of possible hazards as well as subsequent accidents. Each of these hazards, accidents, impacts, and effects are characterized by potential risks that can be reduced but cannot be eliminated.

There are various methods of Environmental Impact Assessment (EIA) and risk identification, for example carbon footprint assessment [69]-[71], environmental life-cycle assessment [74]-[77], water footprint assessment [79], [80], planet boundary assessment [81]-[83] etc.

Several of them as risk screening process [8], risk evaluation matrix [9], hazard environment and safety risk management process [10], HAZOP [11] are used in the oil and gas industry. The main disadvantage of these methods is laborious preparation of modeling and analysis of results, which limits the use of these methods for operational risk management. The methods mostly are not interactive, which makes it difficult to implement "if-then" simulation of scenarios.

To improve risk prediction capabilities, Bayesian networks [97] can be used that allow interactive simulation of the spread of various events probabilities. The method is also used in the 
oil and gas industry [88].

The approach proposed by the authors differs of methods described in [8]-[11] and [87] with a more detailed identification of impact factors, as well as interactivity and accessibility for logistics managers without specific knowledge of mathematics, which allows to use the authors' approach in operational process management. Initially, potential threats and their probabilities are identified, but then a set of related accidents that can cause various impacts on the environment. Traditional methods of environmental impact assessment begin with the assessment of the risks of impacts, disregarding the hazards and accidents that are the causes of impacts. A set of key effects is identified below, which are also evaluated in other environmental impact assessment methods used in the oil and gas industry. This is followed by the determination of the relationships between impacts and effects.

Bayesian risk assessment network nodes initialization data are obtained from related databases and repositories as WOAD [99], ITERATE [100], GTD [101], BSEEE [53], Center of Contemporary Conflict [102] and other. During scenario modeling, the user can change the initial values of the probabilities by tuning the risk assessment network according to the conditions of a specific object.

Some relevant studies can be found in [103], [104], [105] and [106].

Bayesian risk network verification is performed by comparing the analytical calculation with the results of risk modeling. The results of the primary validation cannot be estimated statistically reliably due to the small sample size. As the beta version of the risk assessment methodology continues to evolve, the number of respondents will also increase, and validation opportunities will improve.In addition, the evaluation of the risk assessment method developed by the authors according to the IASAM [56] sustainability model gave a positive and promising result.

The achieved results can be useful for risk management managers in oil and gas companies, regional and territorial development planners, as well as environmental protection specialists.

Further research activities will involve the introduction of additional hazards / accidents and the assessment of their impact, such as cyber attacks. The issue of additional risks posed by unanticipated impacts of digital technologies will be explored. The refinement of the initial values of the risk probability spread network will be continued. The usefulness of machine learning use to determine risk values and their intervals will be considered.

\section{ACKNOWLEDGMENT}

The article publication is funded by LZP-2020/2-0397 "Latent Impacts on Digital Technologies Sustainability Development Assessment (LIASAM)".

\section{References}

[1] British Petroleum. (2020). Statistical review of World energy $2020 \quad\left(69^{\text {th }} \quad\right.$ ed. $) \quad$ [Online]. Available: https://www.bp.com/content/dam/bp/businesssites/en/global/corporate/pdfs/energyeconomics/statistical-review/bp-stats-review-2020-fullreport.pdf

[2] Oil Information: Overview. (2019). Available: https://iea.blob.core.windows.net/assets/9faca21e-8f10$43 \mathrm{c} 0-\mathrm{a} 7 \mathrm{da}-$ bab0c275773f/Oil_Information_2019_Overview.pdf

[3] N. Sonnichsen. (2021). Largest oil consumption worldwide by country 2019 [Online]. Available: https://www.statista.com/statistics/271622/countries-withthe-highest-oil-consumption-in-2012/

[4] US Energy Information Administration. (2020). Oil and petroleum products explained [Online]. Available: https://www.eia.gov/energyexplained/oil-and-petroleumproducts/use-of-oil.php

[5] J. Schneider, S. Ghettas, N. Merdaci, M. Brown, J. Martyniuk, W. Alshehri, and A.Trojan, "Towards sustainability in the oil and gas sector: Benchmarking of environmental, health, and safety efforts," Journal of Environmental Sustainability, 3(3), pp. 103-117, 2013.

[6] GlobeNewswire. (2021). Global \$7425.02 billion oil and gas markets, 2015-2020, 2020-2025F, 2030F [Online]. Available: https://www.globenewswire.com/newsrelease/2021/03/04/2187025/0/en/Global-7425-02-

Billion-Oil-and-Gas-Markets-2015-2020-2020-2025F2030F.html

[7] M. Albu, "Considerations regarding environmental aspects of risk management in the oil and gas industry," in Proc. of Advanced Engineering Forum, vol. 27, 2018, pp. 213-218.

[8] J. L. Hawksley. (2012). Risk management practices in the process industry, Report number 18, EPSC Safety Management Systems Sub-committee [Online]. Available:

https://epsc.be/Documents/Reports/EPSC+Reports+Avail able/_report18.pdf

[9] M. Henderson. (2014). Hazard identification and task risk assessment for non-routine work [Online]. Available: https://www.bp.com/content/dam/bp/countrysites/en_au/australia/home/who-we-are/control-ofwork/gen-9a-hazard-identification-task-risk-assessmentnon-routine-work-guide.pdf

[10] J. Bruney. (2014). Risk management at Chevron [Online]. Available: https://docplayer.net/11904319-Riskmanagement-at-chevron.html

[11] Guidelines for conducting HAZOP studies. (2015). Saudi Aramco HAZOP guidelines [Online]. Available: https://documents.pub/document/hazop-saudi-aramcohazop-guidelines.html

[12]E. Ginters, A. Aizstrauts, and R.M. Aguilar, "Sociotechnical aspects of policy simulation," Handbook 
of Research on Advanced ICT Integration for Governance and Policy Modeling, 2014, pp. 113-128.

[13] S. Lisitsa, A. Levina, and A. Lepekhin, "Supply-chain management in the oil industry," in E3S Web Conferences, vol.110, 2018, pp. 1-10.

[14] M. E. Hansena and E. Dursteler. (2017). Pipelines, rails \& trucks [Online]. Available: https://www.strata.org/pdf/2017/pipelines.pdf

[15]R. E. J. Schnurrand and T. R. Walker, "Marine transportation and energy use," Reference Module in Earth Systems and Environmental Sciences, Elsevier, 2019.

[16]N. Sonnichsen. (2020). Crude oil storage availability worldwide by type 2020 [Online]. Available: https://www.statista.com/statistics/509052/globalavailable-oil-storage-capacity-by-type/

[17]E. Gupteand and A. Richier. (2020). Traderslook to South Africa's Saldanha Bay for crude storages supply glutlooms [Online]. Available: https://www.spglobal.com/platts/en/marketinsights/latest-news/oil/032420-traders-look-to-southafricas-saldanha-bay-for-crude-storage-as-supply-glutlooms

[18]N. Sonnichsen. (2021). Oil production - global distribution 2019 [Online]. Available: https://www.statista.com/statistics/277621/distribution-ofglobal-oil-production-by-region/

[19] S. Mokhatab and W. A. Poe, "Environmental aspects of the natural gas supply chain," Handbook of Natural Gas Transmission and Processing, Elsevier, 2012, pp. 619678.

[20] M. Christou and M. Konstantinidou, "Safety of offshore oil and gas operation: Lesson from past accident analysis," in JRC Scientific and Policy Reports (EUR $25646 \mathrm{EN}), 2012$.

[21] A. Jernelov and O. Linden, "Ixtoc I: A Case study of the world's largest oil spill," AMBIO: A Journal of the Human Environment, 10 (6), pp. 299-306, 1981.

[22]E. J. Francis, "The Alexander L. Kielland disaster revisited: A Review by an experience welding engineer of the catastrophic North Sea platform collapse," Journal of Failure Analysis and Prevention, Jul. 2019.

[23] M. E. Pate-Cornell, "Risk analysis and risk management for offshore platforms: Lessons from the Piper Alpha incident," Journal of Offshore Mechanics and Artic Engineering, 115 (3), pp. 179-190, 1993.

[24]M. E. Pate-Cornell, "Learning from the Piper Alpha accident: A Postmortem analysis of technical and organizational factors," Society for Risk Analysis, vol. 13 (2), pp. 215-232, 1993.

[25] N. Mostafawi, "How severely was the Persian Gulf affect by oil spills following the 1991 Gulf War?" Environmental Geology, 40, pp. 1185-1191, 2001.

[26] J. Beyer, H. C. Trannum, T. Bakke, P. V. Hodson, and T. K. Collier, "Environmental effect of Deepwater Horizon oil spill: A review," Marine Pollution Bulletin, vol. 110 (1), pp. 28-51, 2016.

[27] J. B. Mariano and E. L. La Rovere, "Environmental impact of oil industry," in Encyclopedia of Life Support Systems (EOLSS), Petroleum Engineering Downstream, UNESCO: EOLSS Publishers, 2017, vol.5, pp. 226-260.

[28] A. J. Krupnick and I. Echarte. (2017). Induced seismicity impacts of unconventional oil and gas development [Online]. Available: https://media.rff.org/documents/RFFRpt-ShaleReviews_Seismicity_0.pdf

[29] M. Torhaug, "Petroleum supply vulnerability due to terrorism at North Sea oil and gas infrastructures," in Protection of Civilian Infrastructure from the Acts of Terrorism, Springer, 2006, vol. 12, pp. 73-84.

[30] Opus Kinetic. (2017). Environmental sustainability in oil and gas industry [Online]. Available: https://www.opuskinetic.com/2017/08/environmentalsustainability-in-oil-gas-industry/

[31] M. Fossheim. (2012). Environmental risks when extracting and exporting oil and gas [Online]. Available: https://bellona.org/assets/fil_Chapter_3._Environmental_r isks_when_extracting_and_exporting_oil_and_gas.pdf

[32] J. O. Robertson, G. V. Chilingar, L. F. Khilyuk, and B. Endres, "The environmental aspects of oil and gas production subsidence," Energy Source Part a Recovery Utilization and Environmental Effects, vol. 34 (8), pp. 756-773, 2012.

[33] T. Pelton (2019). Air pollution from growing oil and gas industry in West Texas exceeds health standards [Online]. Available: https://environmentalintegrity.org/news/airpollution-from-growing-oil-and-gas-industry-texas/

[34] S. Kumar, "Acid rain-the major cause of pollution: Its causes, effects," International Journal of Applied Chemistry, 13(1), pp. 53-58, 2017.

[35] S. Sivaramanan. (2015). Acid rain, causes, effects and control strategies [Online]. Available: https://www.researchgate.net/publication/275344491_AC ID_RAIN_CAUSES_EFFECTS_AND_CONTROL_STR ATEGIES channel $=$ doi\&linkId $=553 \mathrm{a} 3 \mathrm{e} 250 \mathrm{cf} 2 \mathrm{c} 415 \mathrm{bb} 073$ 249\&showFulltext=true

[36]D. Frommer and A. Torem, "The petroleum industry and the marine habitat: The Exxon Valdez catastrophe and California's option," Environmental Law and Policy Journal,13(2), pp. 11-14, 1990.

[37] A. Necci, S. Tarantola, B. Vamanu, E. Krausmann, and L. Ponte, "Lessons learned from offshore oil and gas incidents in the Arctic and other ice-prone seas," Ocean Engineering, 185(1), pp. 12-26, 2019.

[38] J. Pitkin, "Oil, oil, everywhere: Environmental and human impacts of oil extraction in the Niger delta," Pomona Senior Theses, 88, Pomona College, 2013.

[39] G. Luciani, "Armed force conflict and security of oil and gas supplies," in CEPS Working Document No. 352, 2011, pp. 1-26. 
[40]B. Fattouh, "How secure is Middle East oil supplies?" in Oxford Institute for Energy Studies, 2007, pp. 1-30.

[41]M. Torhaug, "Petroleum supply vulnerability due to terrorism at North Sea oil and gas infrastructures," in Protection of Civilian Infrastructure from Acts of Terrorism. NATO Security through Science Series. Springer, 2006, pp. 73-84.

[42] K. Ashild and L. Brynjar. (2001). Terrorism and oil - an explosive mixture? A survey of terrorist and rebel attacks on petroleum infrastructure 1968-1999 [Online]. Available: https://ffipublikasjoner.archive.knowledgearc.net/bitstream/handle/ 20.500.12242/886/0104031.pdf? sequence $=1 \&$ is Allowed $=\mathrm{y}$

[43] F. Steinhausler, P. Furthner, W. Heidegger, S. Rydell, and L. Zaitseva, "Security risks to the oil and gas industry: Terrorist capabilities," Strategic Insights, vol. 7(1), 2008.

[44] C. Kollias, C. Kyrtsou, and S. Papadamou, "The effects of terrorism and war on the oil and prices - stock indices relationship," Economics of Security Working Paper 57, DIW, Berlin, 2011.

[45]AGI. (2018). Induced seismicity from oil and gas operations [Online]. Available: https://www.americangeosciences.org/geosciencecurrents/induced-seismicity-oil-and-gas-operations

[46] G. Foulger, M.Wilson, J. Gluyas, B. R. Julian, and R. Davies, "Global review of human-induced earthquakes," Earth-Science Reviews, 178, pp. 438-514, 2018.

[47]Zurich Risk Engineering. (2015). Man-made earthquakes - a manageable risk? [Online]. Available: http://www.zurichservices.com/zsc/reel.nsf/64253a2e432 b3e82c12571fe00451040/1c7fe19faf49d33ec1257ede004 5e726/\$FILE/ManMade_EQ.pdf

[48] A. Saddek. (2016). A guide to failure analysis for the oil and gas industry [Online]. Available: https://ewi.org/wpcontent/uploads/2016/02/Sadek-Guide-to-FialureAnalysis-for-OG-Industry-R2.pdf

[49] M. Alkhaldi, C. Pathirage, and U. Kulatunga, "The role of human error in accidents within oil and gas industry in Bahrain," in Proc. of $13^{\text {th }}$ International Postgraduate Research Conference (IPGRC), Salford, Machester, 2017, pp. 822-834.

[50] M. J. Hoover, "Incidents associated with oil and gas operations. Outer Continental Shelf 2000", OCS Report 2002-016, 2002, pp. 1-112.

[51] SynergenOG. (2018). Critical lessons from 6 major oil and gas industry accidents [Online]. Available: https://synergenog.com/2018/06/11/critical-lessons-from6-major-oil-and-gas-industry-accidents/

[52]C. Ko, H. Lee, K. Kim, and W. B. Lee, "Quantitative risk assessment integrated with dynamic process simulation for reactor section in heavy oil desulfurization process," Journal of Loss Prevention in the Process Industries, 66, pp. 1-12, 2020.
[53]BSEE. (2020). Offshore Incidents Statistics [Online]. Available: https://www.bsee.gov/stats-facts/offshoreincident-statistics

[54]C. Stevens, "Sustainability assessment methodologies," in Workshop on Sustainability Assessment Methodologies, Amsterdam, 2008, pp. 1-11.

[55] J. Pope, D. Annandale, and A. M. Saunders, "Conceptualizing sustainability assessment," Environmental Impact Assessment Review, vol. 24(6), pp. 595-616, 2004.

[56]E. Ginters and D. Aizstrauta, "Technologies sustainability modeling," In Advances in Intelligent Systems and Computing, Springer International Publishing AG, 2018, vol. 746, pp. 659-669.

[57] J. Glassson, R. Therivel, and A. Chadwick, "Introduction to environmental impact assessment", $3^{\text {rd }}$ ed, London and New York: Taylor and Francis Group Print, 2005.

[58]D. R. Turner and L. Canter, "The use of environmental indicators for impact assessment in compliance with the National environmental policy act," Nuclear Regulatory Commission, TX, USA, 2008.

[59] P. Ksiezak and B. Fischbach, "Triple bottom line: The pillars of CSR," Journal of Corporate Responsibility and Leadership, 4(3), pp. 95-110, 2018.

[60] O. A. Amos, E. Uniamikogbo, and G. Oghogho, "Sustainability and triple bottom line: An overview of two interrelated concepts," Igbinedion University Journal of Accounting, 2, pp. 88-126, 2016.

[61] L. Munoz-Pascual, C. Curado, and J. Galende, "The triple bottom line on sustainable product innovation performance in SMEs: A mixed methods approach," Sustainability, 11(6): 1689, 2019.

[62]N. Gorlenko, M. Murzin, and R. Belyaevsky, "Assessment of environmental risks at oil and gas production companies using an integrated method," in E3S Web Conferences, vol. 174, 2020, pp. 1-7.

[63]F. Vanclay, "The triple bottom line and impact assessment: How do TBL, EIA, SIA, SEA and EMS relate to each other?" Journal of Environmental Assessment Policy and Management, 6(3), pp. 265-288, 2004.

[64] A review of ecological assessment case studies from a risk assessment perspective, EPA 630-R-94-003, U.S. Environmental Protection Agency, vol. 2, 1994.

[65] A. K. Meena and T. K. Yadav, "What is ecological footprint and why is it important?" Agrobios Newsletter, 18(1), pp. 25-26, 2019.

[66]R. Itten and N. Jungbluth. (2012). A questionnaire for calculating ecological footprint [Online]. Available: https://www.yumpu.com/en/document/view/4169817/aquestionnaire-for-calculating-ecological-footprint-esuservices

[67]British Petroleum. (2019). Energy with purpose. BP sustainability report [Online]. Available: https://www.bp.com/content/dam/bp/business- 
sites/en/global/corporate/pdfs/sustainability/groupreports/bp-sustainability-report-2019.pdf

[68] Shell. (2020). Sustainability report 2020 [Online]. Available: https://www.shell.com/sustainability.html

[69]D. Pandey, M. Agarwal, and J. S. Pandey, "Carbon footprint: Current methods of estimation," Environmental Monitoring and Assessment, vol. 178, pp. 135-160, 2011.

[70]P. Bhatia. (2008). Methodologies for measuring the carbon footprint [Online]. Available: https://www.itu.int/dms_pub/itut/oth/06/0F/T060F0000090023PDFE.pdf

[71] J. M. Hudson, B. Silver, M. Kavanagh, L. Fishler, and D. Olson, "CRFPO carbon footprint, FY 2013 Report," U.S. Fish and Wildlife Services, 2014, 17 p.

[72] Saudi Aramco. (2018). Enviro News [Online]. Available: https://www.aramco.com/-/media/publications/environews/2018-28.pdf

[73] Exxon Mobil corporation sustainability case study, Datamonitor, EBSCO, 2010.

[74] S. Joshi, "Product environmental Life-Cycle Assessment using Input-Output techniques", Journal of Industrial Ecology, vol. 3, pp. 95-120, 1999.

[75]IFU. (2021). Life cycle assessment - definition and methodology [Online]. Available: https://www.ifu.com/en/life-cycle-assessment/

[76] O. Jolliet, M. Saade-Sbeih, S. Shaked, A. Jolliet, and P. Crettaz, "Environmental life cycle assessment," CRC Press, Taylor\& Francis Group, 2015.

[77]H. Baumann and T. Rydberg, "Life cycle assessment: A comparison of three methods for impact analysis and evaluation," Journal of Cleaner Production, 2(1), pp. 1320, 1994.

[78] Chevron. (2020). The human energy company. Chevron annual report 2020 [Online]. Available: https://www.chevron.com/-/media/chevron/annualreport/2020/documents/2020-Annual-Report.pdf

[79] A. Y. Hoekstra, A. K. Chapagain, M. M. Aldaya, and M. M. Mekonnen, "The water footprint assessment manual," London: Earthscan, 2011, 224 p.

[80] WaterCalculator. (2017). The water footprint of energy [Online]. Available: https://www.watercalculator.org/footprint/the-waterfootprint-of-energy/

[81] W. Steffen, K. Richardson, J. Rockstrom et al., "Planetary boundaries: Guiding human development on a changing planet," Science, 347 (6223), 2015.

[82]F. Biermann and R. E. Kim, "The boundaries of the planetary boundary framework: A critical appraisal of approaches to define a "Safe Operating Space" for humanity," in Annual Review of Environment and Resources, 2020, pp. 497-521.

[83] J. Rockstorm, W. Steffen, K. Noone, and A. Perrson et al., "Planetary boundaries: Exploring the safe operating space for humanity," Ecology and Society, 14(2):32, 2009.
[84]R. Aetdinova, O. Chorosova, and I. Maslova, "Risk assessment method of HEI," Advances in Economics, Business and Management Research, 2020, vol. 128, pp. 2678-2684.

[85] All hazards risk assessment. (2013). Methodology guidelines 2012-2013 [Online]. Available: https://www.publicsafety.gc.ca/cnt/rsrcs/pblctns/ll-hzrdsssssmnt/ll-hzrds-ssssmnt-eng.pdf

[86] M. Horny. (2014). Bayesian networks. Technical Reports 5 [Online]. Available: https://www.bu.edu/sph/files/2014/05/bayesian-networksfinal.pdf

[87] L. Kaikkonen, T. Parviainen, M. Rahikainen, L. Uusitalo, and A. Lehikoinen, "Bayesian networks in environmental risk assessment: A review," Integrated Environmental Assessment and Management, 17(1), pp. 62-78, 2021.

[88] S. M. Deyab, M. Taleb-Berrouane, F. Khan, and M. Yang, "Failure analysis of the offshore process component considering causation dependence," Process Safety and Environmental Protection, 113, pp. 220-232, 2018.

[89] T. Bayes, "An essay toward solving a problem in the doctrine of chances," Philosophical Transactions of the Royal Society of London 53, pp. 370-418, 1764.

[90]D. Heckerman, "A tutorial on learning with Bayesian networks," in Learning in Graphical Models, MIT Press, Cambridge, MA, 1999.

[91]R. S. Kenett and A. De Frenne, "The statistical efficiency conjecture, in applying statistical methods in business and industry - the state of the art," Chichester: John Wiley and Sons, 2008.

[92]X. Bai, R. S. Kenett, and W. Yu, "Risk assessment and adaptive group testing of semantic Web services," International Journal of Software Engineering and Knowledge Engineering, 22 (5), pp. 565-620, 2012.

[93]R. S. Kenett and S. Salini, "Modern analysis of customer satisfaction surveys: with applications using," Chichester: John Wiley and Sons, 2011.

[94]R. S. Kenett, "Risk analysis in drug manufacturing and healthcare," in Statistical methods in healthcare, Chichester: John Wiley and Sons, 2012.

[95]N. Fenton, M. Osman, and S. McLachlan. (2020). Bayesian network analysis of Covid-19 data reveals higher infection prevalence rates and lower fatality rates than widely reported [Online]. Available: https://www.tandfonline.com/doi/full/10.1080/13669877. 2020.1778771

[96] S. McLachlan et al. (2020). The fundamental limitations of COVID-19 contact tracing methods and how to resolve them with a Bayesian network approach [Online]. Available: https://www.researchgate.net/profile/ScottMclachlan

[97]E. Ginters and D. Basdogan, "The use of Bayesian acyclic network to assess the impact of digital technology attributes on sustainability pillars," in Proc. 2021 Fourth 
World Conference on Smart Trends in Systems, Security and Sustainability (WorldS4), London, IEEE, 2021, to be published.

[98] BayesFusion. (2020). GeNIe modeler. User manual. Version 3.0.R2 [Online]. Available: https://support.bayesfusion.com/docs/GeNIe.pdf

[99] DNV. (2021). World offshore accident database - WOAD [Online]. Available: https://www.dnv.com/services/world-offshore-accidentdatabase-woad-1747

[100] Duke. (2021). International terrorism: Attributes of terrorist events (ITERATE) [Online]. https://library.duke.edu/data/sources/iterate

[101] Global Terrorism Database (GTD). (2021). [Online]. Available: https://start.umd.edu/gtd/

[102] Center on Contemporary Conflict. (2021). [Online]. Available: https://calhoun.nps.edu/handle/10945/11070

[103] S. Gerassis, A. Saavedra, J. F. Garcia, J. E. Martin, and J. Taboada, "Risk analysis in tunnel construction with Bayesian networks using mutual information for safety policy decisions," WSEAS Transactions on Business and Economics, pp. 215-224, vol. 14, 2017.

[104] S. M. A. Burney, Q. U. Arifeen, N. Mahmood, and S. A. K. Bari, "Suspicious call detection using Bayesian network approach," WSEAS Transactions on Information Science and Applications, pp. 37-49, vol. 15, 2018.

[105] I. Mekterovic, L. Brkic, and M. Branovic, "A systematic review of data mining approaches to credit card fraud detection," WSEAS Transactions on Business and Economics, pp. 437-444, vol. 15, 2018.

[106] N. Litvinenko, A. Shayakhmetova, and O. Mamyrbayev, "Clusterization by the K-means method with unknown $\mathrm{K}$ and other additional conditions," WSEAS Transactions on Information Science and Applications, pp. 1-7, vol. 16, 2019.

\section{Creative Commons Attribution License 4.0 (Attribution 4.0 International, CC BY 4.0)}

This article is published under the terms of the Creative Commons Attribution License 4.0

https://creativecommons.org/licenses/by/4.0/deed.en_US 